Projets

de paysage

\section{Projets de paysage}

Revue scientifique sur la conception et l'aménagement de l'espace

$8 \mid 2012$

Les concepteurs de jardins et de parcs japonais

\title{
Les jardins paysagers des seigneurs domaniaux de l'époque d'Edo et les manuels relatifs à la composition des jardins
}

Seconde partie : L'apparition de la figure de l'architecte-paysagiste et la transmission du savoir à travers les manuels imprimés

Landscape gardens of the state lords in the Edo period, and handbooks concerning gardens' composition - Second Part: The emergence of the landscape-architect figure, and the conveying of knowledge through printed handbooks

\section{Nicolas Fiévé}

\section{OpenEdition}

Journals

Édition électronique

URL : http://journals.openedition.org/paysage/14405

DOI : $10.4000 /$ paysage. 14405

ISSN : 1969-6124

Éditeur :

École nationale supérieure du paysage de Versailles-Marseille, Institut national des sciences appliquées Centre Val de Loire - École de la nature et du paysage, École nationale supérieure d'architecture et de paysage de Bordeaux, École nationale supérieure d'architecture et de paysage de Lille, Agrocampus Angers

\section{Référence électronique}

Nicolas Fiévé, «Les jardins paysagers des seigneurs domaniaux de l'époque d'Edo et les manuels relatifs à la composition des jardins », Projets de paysage [En ligne], 8 | 2012, mis en ligne le 15 juillet 2012, consulté le 11 mars 2021. URL : http://journals.openedition.org/paysage/14405 ; DOI : https:// doi.org/10.4000/paysage. 14405

Ce document a été généré automatiquement le 11 mars 2021.

Projets de paysage 


\section{Les jardins paysagers des seigneurs domaniaux de l'époque d'Edo et les manuels relatifs à la composition des jardins}

Seconde partie : L'apparition de la figure de l'architecte-paysagiste et la transmission du savoir à travers les manuels imprimés

Landscape gardens of the state lords in the Edo period, and handbooks concerning gardens' composition - Second Part : The emergence of the landscape-architect figure, and the conveying of knowledge through printed handbooks

Nicolas Fiévé

\section{Des paysagistes professionnels, rémunérés pour le travail de conception des jardins}

1 À l'époque d'Edo (1603-1867), la plupart des seigneurs domaniaux habitaient les provinces, parfois bien loin de Kyōto, et les shōguns Tokugawa résidaient à Edo, soit à environ 400 kilomètres de la capitale. L'établissement du système de sankin kōtai 参勤交 代, par lequel le personnel de toutes les maisons avait ainsi l'occasion de vivre à Edo et donc de ne pas réduire son champ de vision aux limites étroites de sa province d'origine, a été l'un des vecteurs les plus efficaces de la diffusion des arts et des connaissances dans tous les domaines du savoir. L'époque d'Edo fut ainsi celle d'une ample circulation des hommes et, pour le sujet qui nous intéresse, des techniques et des savoirs relatifs à l'art des jardins et à l'architecture. Un mouvement qui se faisait dans un premier temps de Kyōto vers le reste du territoire, mais aussi, dès la fin du $\mathrm{XVII}^{\mathrm{e}}$ siècle, des lointaines provinces vers Edo et, par contrecoup, d'Edo vers Kyōto. Bien que l'archipel ait été une longue terre de 1800 kilomètres, la distance, tant physique 
que temporelle, ne semble pas avoir été un obstacle à la diffusion des motifs fondamentaux du jardin et de l'habitat des élites. Si différences stylistiques il y avait, celles-ci n'étaient guère le fruit d'un régionalisme, mais plutôt la conséquence des changements de mode d'une époque.

\section{Kobori Enshū 小堀遠州 (1579-1647)}

2 On sait que certains daimyō sont montés à la ville shōgunale accompagnés de conducteurs de travaux, de jardiniers et d'horticulteurs venus de leur province, afin que ces derniers réalisent les jardins de leurs nouveaux palais. Un homme comme Kobori Masakazu 小堀政一 (1579-1647), resté célèbre sous le nom de Kobori Enshū 遠 州, a été sollicité tout au long de sa vie par de puissants seigneurs, afin qu'il leur fit bénéficier de ses talents et de son goût, si reconnaissables dans la conception de ses jardins. C'est ainsi que Mori Nagatsugu 森長継 (1610-1698), le $2^{\mathrm{e}}$ seigneur du fief de Tsuyama 津山藩, dans la province de Mimasaka 美作国, lui a peut-être demandé de participer à la conception de son jardin de plaisance, ce qu'aucune source n'atteste avec certitude, bien que le jardin s'inspire de celui du palais impérial de Kyōto qu'avait conçu Enshū et que la tradition locale considère Enshū l'auteur de ce jardin. Le Shūraku-en衆楽園 de Tsuyama est une demeure secondaire qui atteignait jadis 7,4 hectares, dont il subsiste encore la partie orientale, composée de 2,8 hectares de jardins paysagers disposés autour d'un étang et de pavillons de plaisance au toit de chaume (figure 1).

Figure 1. Jardin Shūraku-en衆楽園 (2,8 hect.), XVIII siècle, commencé sous Mori Nagatsugu (1610-1698), $2^{\mathrm{e}}$ seigneur du fief de Tsuyama

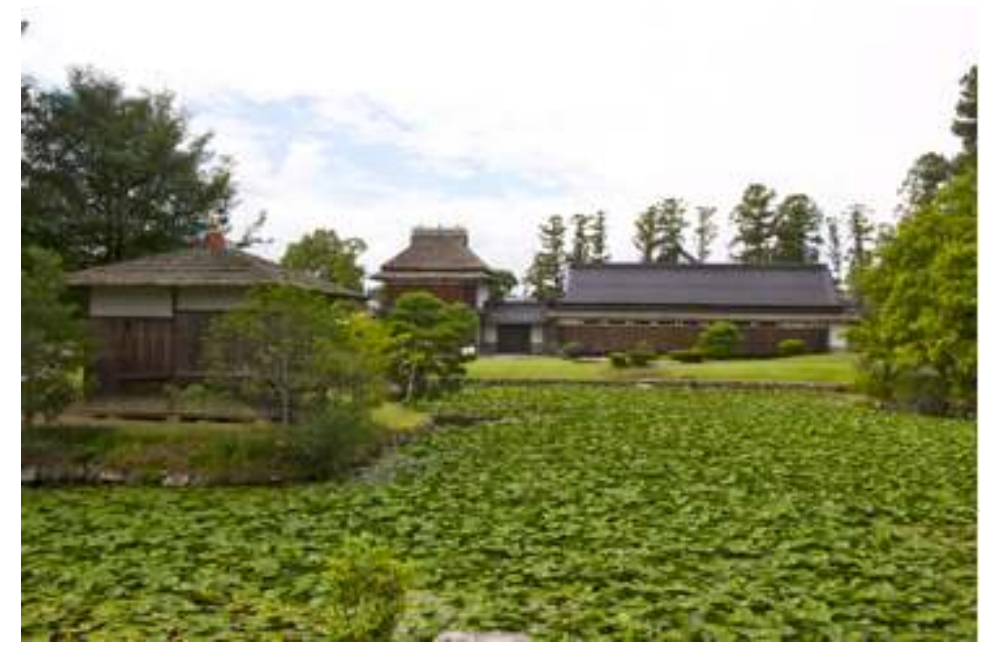

Source : Nicolas Fiévé

3 Kobori Masakazu 小堀政一 est né en 1579 dans la province d'Ōmi 近江国, fils du seigneur du fief de Komuro 小室藩, un petit domaine d'un revenu de 14460 koku de riz. Il épouse à dix-neuf ans la fille aînée du guerrier Tōdō Takatora 藤堂高虎 (1556-1630), encore modeste vassal de Toyotomi Hideyoshi豊臣秀吉 (1537 ?-1598). En 1604, à la mort de son père, le domaine est partagé avec son cadet : fils aîné, il hérite à vingt-six ans d'un revenu de 12000 koku pour le fief de Komuro, alors que son frère reçoit une terre d'une valeur de 2000 koku, ainsi que de la charge d'administrateur qu'occupait son père au château de Matsuyama 松山城, dans la province de Bichū 微表国 (où se 
trouve l'actuel château d'Okayama). Lui échoit alors la responsabilité de la restauration du château.

Figure 2. Jardin du palais Sentō 仙洞御所, palais de l'empereur retiré à Kyōto, 1606 (Keichō 11)

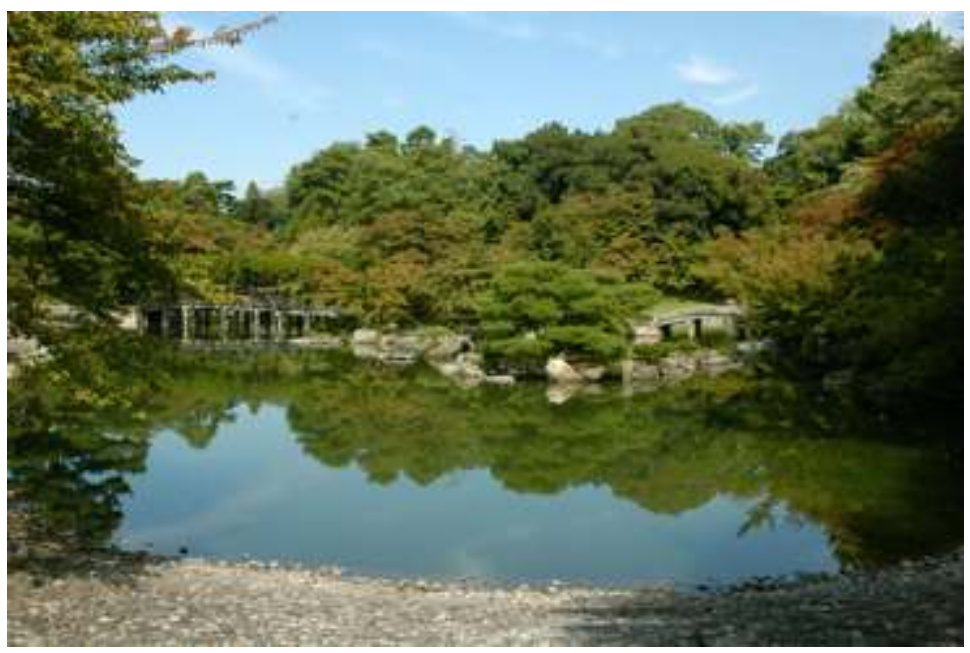

Source : Nicolas Fiévé

4 Ses qualités en matière d'architecture semblent vite reconnues. Sans doute aidé par son beau-père devenu dans le même temps un fidèle vassal des Tokugawa, il est nommé en 1606 (Keichō 11) préfet des travaux, sakuji bugyō 作事奉行, du palais de l'empereur retiré, le palais Sentō 仙洞御所, à Kyōto² (figure 2), et, deux ans plus tard, responsable des travaux du château de Sunpu 駿府城, où demeure alors Tokugawa Ieyasu徳川家康 (1543-1616). Enshū n'a alors que vingt-neuf ans. Cette tâche semble couronnée de succès, puisqu'il est alors promu au titre de gouverneur de la province de Tōtōmi 遠江 国, aussi appelée Enshū 遠州. C'est à partir de cette période que Masukaza prend le nom d'Enshū ; il vient tout juste de fêter ses trente ans.

5 La proximité de Takatora avec Tokugawa Ieyasu a incontestablement bénéficié à la carrière d'Enshū. Comme son beau-père, il obtient la charge d'administrateur des travaux de plusieurs places fortes, dont les plus importantes en termes de stratégie militaire, puisqu'il s'agissait des forteresses qui contrôlaient l'approvisionnement maritime et fluvial de la capitale Kyōto et les principales voies de communication entre le Kantō et le Kansai. Enshū est successivement nommé préfet de la construction, fushin bugyō普請奉行, du donjon du château de Nagoya, Nagoya-jō tenshukaku 名古屋城天守閣 (le château de la branche Tokugawa du fief d'Owari 尾張藩), du shoin de l'enceinte centrale du château de Fushimi, Fushimi-jō honmaru shoin 伏見城本丸書院, des édifices de l'enceinte centrale du château d'Ōsaka, ōsakajō honmaru 大阪城本丸, des bâtiments de la seconde enceinte du château de Nijō, Nijōj-jō二条城, de la construction d'un pavillon de thé et de son jardin dans l'enceinte ouest du château d'Edo, Edo-jō Nishinomaru 江戸城西の丸3.

6 Lors de ces travaux, Enshū faisait office à la fois d'administrateur financier et d'architecte. S'il administrait les chantiers, il en était aussi un véritable concepteur, dessinant dans le même temps les jardins de ces palais, comme ce fut le cas au château de Nijō ou à Nagoya. En 1623, il est nommé préfet de Fushimi, Fushimi bugyō 伏見奉行, sa plus haute charge, qu'il occupe jusqu'à son décès en 1647. 
7 Au cours de ces années, alors qu'il a désormais une position solidement établie, Enshū est devenu un proche du maître de thé Furuta Oribe 古田織部 (1544-1615), dont il était le disciple. Oribe était alors l'un des hommes les plus influents de son temps dans le monde des hommes de thé, chajin 茶人. Guerrier de rang modeste, qui avait servi les chefs militaires Oda Nobunaga et Toyotomi Hideyoshi, Oribe avait lui-même été le disciple, une dizaine d'années durant, de Sen no Rikyū 千利休 (1522-1591), le maître fondateur de la cérémonie du thé, dont il est un des sept disciples directs. Selon le Tennōjiya kaiki 天王寺屋会記 (Réunions [de thé] de la maison de Tennōji) et l'Imai Sōkyū chanoyu nikki kakinuki 今井宗久茶湯日記書抜 (Extraits du journal des cérémonies du thé d'Imai Sōkyū), Oribe avait été invité par Toyotomi Hideyoshi à plusieurs rencontres de thé au château d'ōsaka, en présence des maîtres les plus importants de son temps: Rikyū, Imai Sōkyū 今井宗久 (1520-1593), Yamanoue Sōji 山上宗二 (1544-1590).

8 L'enseignement de Furuta Oribe a fait d'Enshū un homme de thé accompli, tout en le rapprochant des lettrés, des moines et des artistes de Kyōto, qu'il côtoyait sans relâche. Son nom est associé aux personnages illustres de l'élite artistique de son temps: le prince Hachijō no miya Toshihito 八条宮智仁 (1579-1629), Konoe Enzan 近衛応山 (1599-1649), quatrième fils de l'empereur Goyōzei et disciple d'Oribe, le maître de thé Hosokawa Sansai細川三斎 (1563-1646) ou le calligraphe Hon.ami Kōetsu本阿弥光悦 (1558-1637). Au milieu de ce foyer artistique, Enshū poursuit ses fonctions de préfet tout en s'adonnant aux arts : art du thé, poésie, calligraphie, céramique, création de jardins et de pavillons de thé. Il conçoit alors plusieurs jardins de temples de Kyōto, comme celui du Konchi-in 金地院, remarquable pour sa composition de pierres sèches du couple de l'île-grue et de l'île-tortue (figure 3). Il devient aussi l'instructeur en matière de cérémonie du thé du $3^{\mathrm{e}}$ shōgun Tokugawa Iemitsu徳川家光 (shōgun de 1623-1651).

Figure 3. Jardin du temple Konchi-in 金地院, œuvre de Kobori Enshū, première moitié du XVII siècle

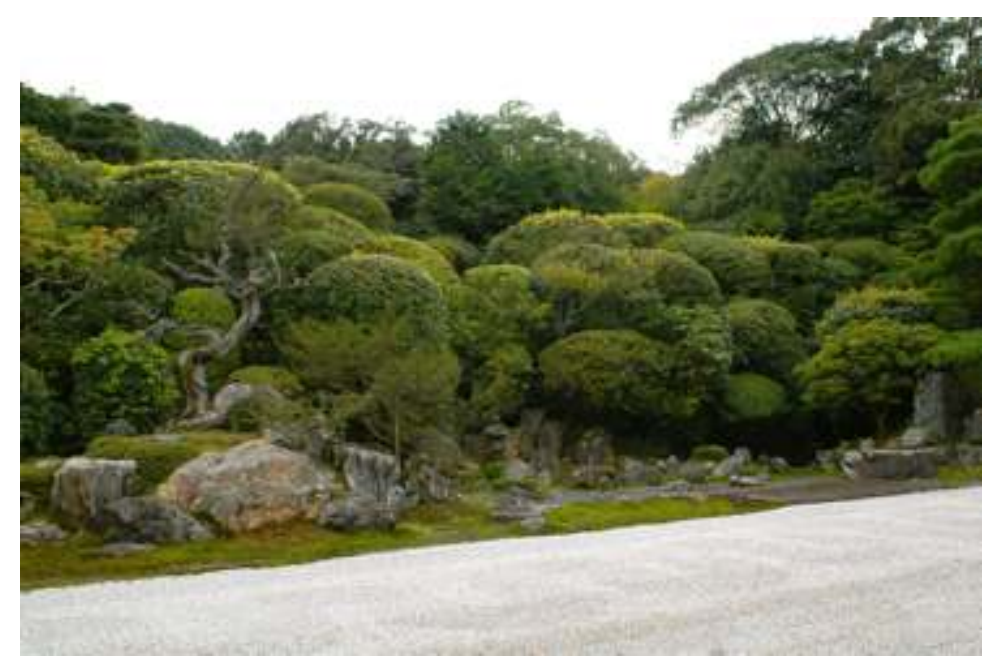

À gauche une île-tortue, à droite une île-grue

Source : Nicolas Fiévé

9 Le milieu artistique du Kyōto de la première moitié du XVII ${ }^{e}$ siècle, auquel Enshū appartient, est caractérisé par une étroite association des élites aristocratiques et militaires. En tant que maître de thé et concepteur de jardins, Enshū demeure probablement celui qui fut le plus à la croisée de ces influences, dont il sait faire la 
synthèse : esthétique raffinée de la Cour, comme au jardin du palais impérial ou à la villa détachée de Katsura ${ }^{4}$, influence de l'ascétisme zen, comme au pavillon de thé Hassō no seki 八空席 (le siège des Huit consciences [du bouddhisme]) du temple Konchi-in ${ }^{5}$, inspiration de la peinture de paysage chinoise et des maîtres zen de Kyōto, comme aux jardins du château de Nijō (figure 4) et du temple Konchi-in (figure 3). De ce point de vue, et s'il est bien l'auteur des œuvres qui lui sont attribuées, Enshū demeure sans aucun doute l'architecte-paysagiste qui a le plus profondément marqué l'évolution de l'art des jardins du début de l'époque d'Edo.

Au château de Nijō, Nijō-jō 二条城, Enshū ne conçoit pas entièrement le jardin, mais il a la charge de son remaniement, comme de la construction de l'aile qui a accueilli l'empereur Gomizunoo 後水尾天皇 (r. 1611-1629). L'ancien jardin n'était visible que de la partie des édifices aujourd'hui encore existants. Les appartements de l'empereur étant bâtis de l'autre côté de la pièce d'eau, Enshū a fait remodeler le jardin afin qu'il puisse être contemplé de part et d'autre, déplaçant et ajoutant de nombreux blocs de pierre (figure 5).

Figure 4. Assemblages de pierres et chute d'eau du jardin Ni no maru teien 二の丸庭園 (1624-1626) du château de Nijō

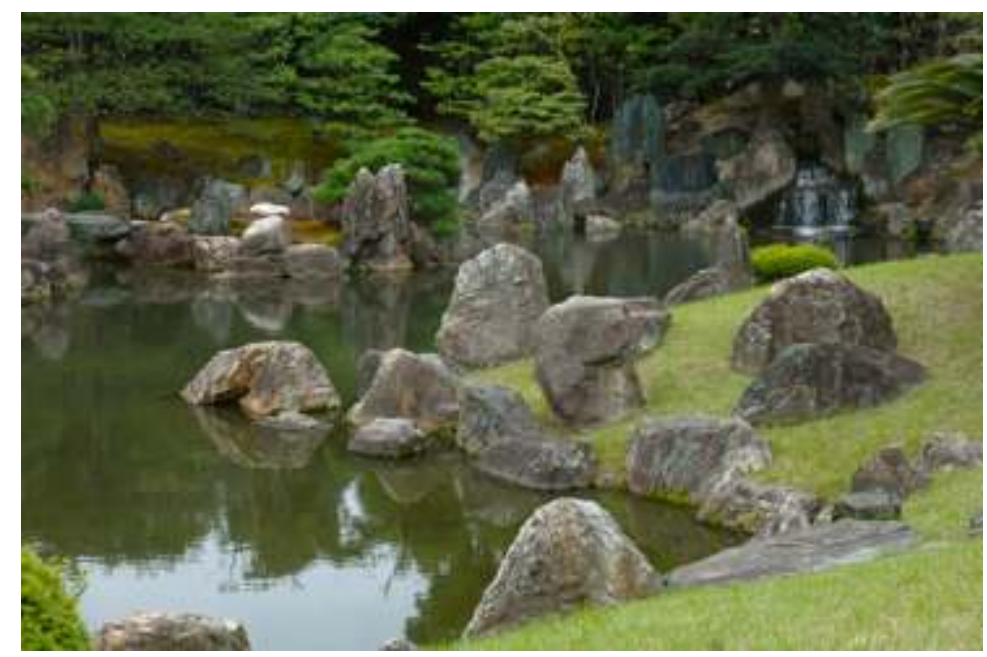

En 1624 (Kan.ei 1), le 3e shōgun lemitsu (1604-1651) et son prédécesseur, le shōgun retiré Hidetada, se lancèrent dans de grands travaux de réfection du château, afin d'y recevoir l'empereur Gomizunoo. Les travaux de réfection débutèrent en 1624 pour s'achever en 1626 (Kan.ei 3).

Source : Nicolas Fiévé

11 Le jardin actuel couvre une superficie de 1350 tsubo 坪 (4 $\left.455 \mathrm{~m}^{2}\right)$, sur laquelle l'étang représente 480 tsubo $\left(1594 \mathrm{~m}^{2}\right)$, soit un tiers environ. Il est de style chisen kaiyū shiki 池 泉迴遊式, c'est-à-dire un «jardin promenade organisé autour d'un étang et d'une source ». La très grande majorité des pierres sont des roches de montagne, adjointes de pierres bleues provenant de l'île de Shikoku. Rares sont les galets de torrents. On trouve relativement peu d'essences végétales dans le jardin actuel: des pins 松, des cerisiers du Japon, sakura 桜, des cycas du Japon, sotetsu ${ }^{6}$ 蘇鉄 (cycas revoluta). 
Figure 5. Plan du château de Nijō

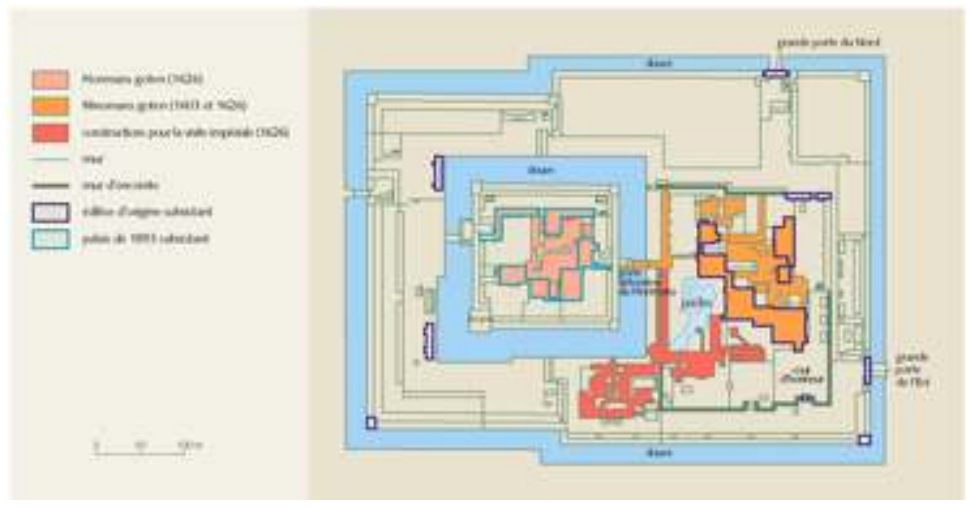

Source : Nicolas Fiévé

Les ponts du jardin sont faits d'une seule pierre, longue et légèrement galbée (figure 6), une technique de taille inaugurée à l'époque de ce jardin (les pierres semblables du pavillon d'Argent remontent des restaurations de l'époque d'Edo) et qui sera reprise avec brio dans les travaux d'agrandissement du jardin de la villa Katsura, vers les années 1640-1650.

Figure 6. Pont de pierre dans le jardin Ni no maru teien 二の丸庭園 (1624-1626) du château de Nijō

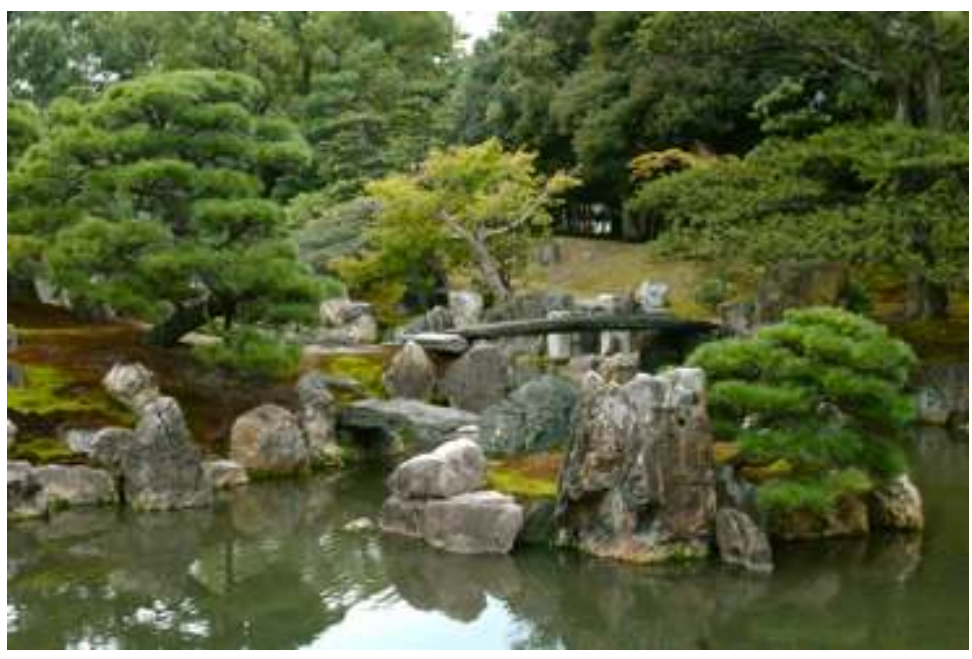

Source : Nicolas Fiévé

13 Si les jardins des temples de l'époque Muromachi (1333-1573) s'inspiraient très directement des peintures de paysage chinoises, le jardin du château de Nijō, comme les peintures des portes coulissantes, fusuma 襖, inaugure un style de jardin dit de " paysage à la japonaise », wayō sansui 和洋山水. Certes, le paysage du jardin fait partie de la tradition des jardins montrant les îles des Immortels, Hōrai yōshiki 蓬莱様式, mais ici l'île centrale surmontée d'un grand pin rouge et associée à Penglai 蓬莱山 devient le centre unique des points de vue du jardin, ce qui est assez nouveau.

Des sources de l'époque d'Edo associent le jardin et l'île Penglai au motif chinois de 《Grand général », daishōgun大将. Les « Huit campements », hachijin 八陣, représentés dans ce diagramme selon la rose des vents (figure 7), sont à l'origine une formation militaire appréciée dans la Chine antique, notamment par Zhuge Liang 諸葛亮 
(181-234), un stratège allié à Liu Bei 劉備 (r. 221-223), le fondateur du royaume de Shu 蜀, à l'époque des Trois royaumes. Ce stratège était aussi considéré comme un devin hors pair, et de nombreuses techniques de divination militaire lui ont été attribuées. Selon le diagramme, Penglai, l'île des Immortels située au centre de l'étang et du jardin, est associée au Grand général, c'est-à-dire le shōgun Tokugawa, lui-même, protégé dans les directions cardinales par: l'Oiseau, au sud, associé dans le jardin à l'île-grue; le Serpent au nord, associé dans le jardin à l'île-tortue; le Dagon à l'est, associé dans le jardin à la presqu'île, dejima 出嶋, qui adopte la forme d'un dragon; le Tigre, à l'ouest, associé dans le jardin au pont de pierre. Aucun document ancien n'atteste cependant que ce motif faisait partie du dispositif qui avait prévalu à la conception du jardin. Par ailleurs, dans la configuration actuelle, il semble que l'île-tortue soit au sud et l'île-grue au nord ${ }^{7}$.

Figure 7. Le motif du Grand général, daishōgun大将軍

\begin{tabular}{|c|c|c|c|c|}
\hline N-O & & $\mathrm{N}$ & & $\mathrm{N}-\mathrm{E}$ \\
\hline & 天陣 & 蛇陣 & 雲陣 & \\
\hline $\mathrm{O}$ & 虎陣 & 大将 & 龍陣 & $\mathrm{E}$ \\
\hline S-O & 地陣 & 鳥陣 & 風陣 & \\
\hline
\end{tabular}

Pour Shigemori Mirei, le style de disposition des pierres pourrait évoquer d'autres jardins réalisés par le jardinier Kentei 賢庭 (dates inconnues, époque Momoyama, début Edo) avec lequel Kobori Enshū a travaillé, mais il ne cite aucune source qui confirmerait cette hypothèse. Kentei avait été le jardinier des jardins des temples Entoku-in 圓徳寺, Kōdai-ji 高台寺 et Sanbō-in 三宝院 du Daigo-ji 醍酤寺, à Kyōto ${ }^{8}$.

\section{Ueda Sōko 上田宗箇 (1563-1650)}

Un homme comme Ueda Sōko 上田宗箇 (1563-1650), Kamemaru 亀丸de son prénom de naissance, fut également sollicité par de grands daimyō pour la conception de leurs jardins. Ce guerrier, qui avait servi Toyotomi Hideyoshi 豊臣秀吉 (1537-1598) avant la bataille de Sekigahara et qui est entré par la suite au service du clan Asano 浅野氏, avait étudié le thé, comme son condisciple Kobori Enshū, avec les maîtres les plus renommés de son temps : Sen no Rikyū 千利休 (1522-1591), puis Furuta Oribe 古田織部 (1544-1615). 
Figure 8. Jardin du Ni no maru goten 二の丸御殿 du château de Nagoya 名古屋城, œuvre d'Ueda Sōko 上田宗箇 (1563-1650), début XVII ${ }^{\mathrm{e}}$ siècle

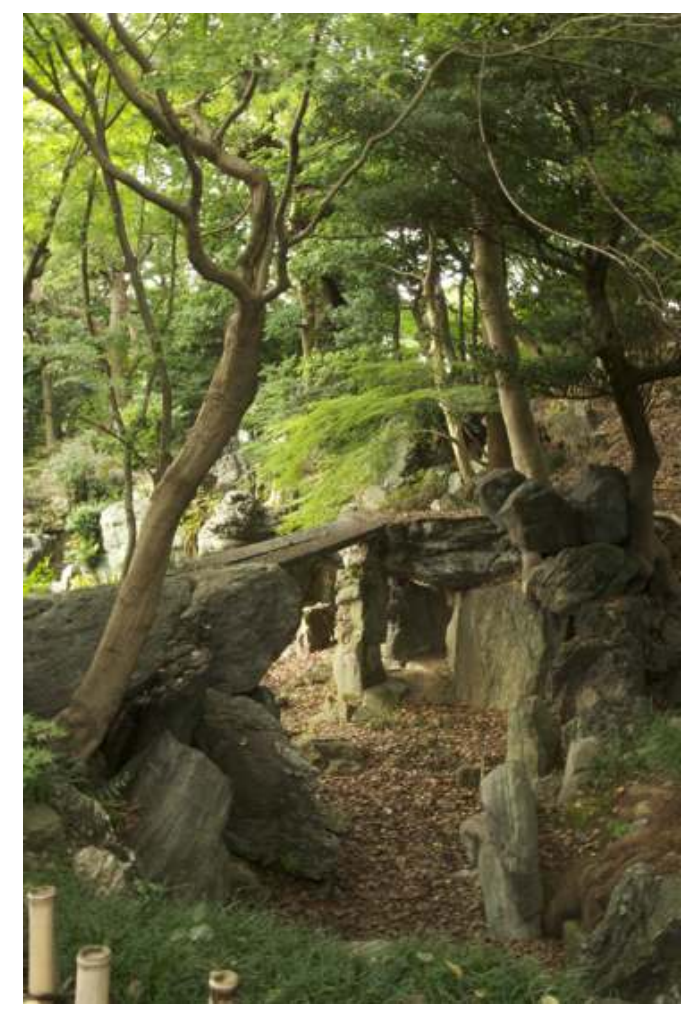

Source : Nicolas Fiévé

Sōko a conçu, au cours des années Genwa (1615-1623), le jardin du Ni no maru goten二の 丸御殿 (Palais de la deuxième enceinte) du château de Nagoya 名古屋城 ${ }^{9}\left(3500 \mathrm{~m}^{2}\right)$ (figure 8), celui du Ni no maru goten du château de Wakayama 和歌山城 $\left(8500 \mathrm{~m}^{2}\right)$ (figure 10) et le jardin du château de Tokushima 徳島城 $\left(5025 \mathrm{~m}^{2}\right)$ (figure 9). Des compositions réalisées toutes les trois dans le style original de l'école Kyokukan, Kyokukan-ryū 玉澗流, une tradition paysagère qui tire son nom du peintre chinois Ruofen (jap. Jakubun) 若芬 (1127-1279), dit Yujian 玉澗 (Kyokukan en japonais). Moine et peintre de la fin de la dynastie des Song du Sud et du début de celle des Yuan, Yujian avait créé un style de montagnes et de roches particulièrement escarpées qu'Ueda Sōko aimait représenter dans ses jardins. Yujian reste célèbre au Japon notamment pour une vue du Mont $\mathrm{Lu}$ 慮山, exécutée d'après un poème de Li Bai 李白 (701-762) et intitulée Lushan guanbao (jap. Rōzan kanbaku) 慮山観瀑 (La chute d'eau vue du Mont Lu). Dans le jardin du Ni no maru goten du château de Nagoya, Sōko symbolise à l'aide de roches de grande dimension une gorge escarpée, coincée entre deux montagnes et que traverse un haut pont de pierre, dont l'effet pictural est des plus saisissants malgré un dispositif qui ne dépasse guère trois mètres de hauteur (figure 8). 
Figure 9. Jardin du château de Tokushima 徳島城, œuvre d'Ueda Sōko 上田宗箇 (1563-1650), début xvII siècle

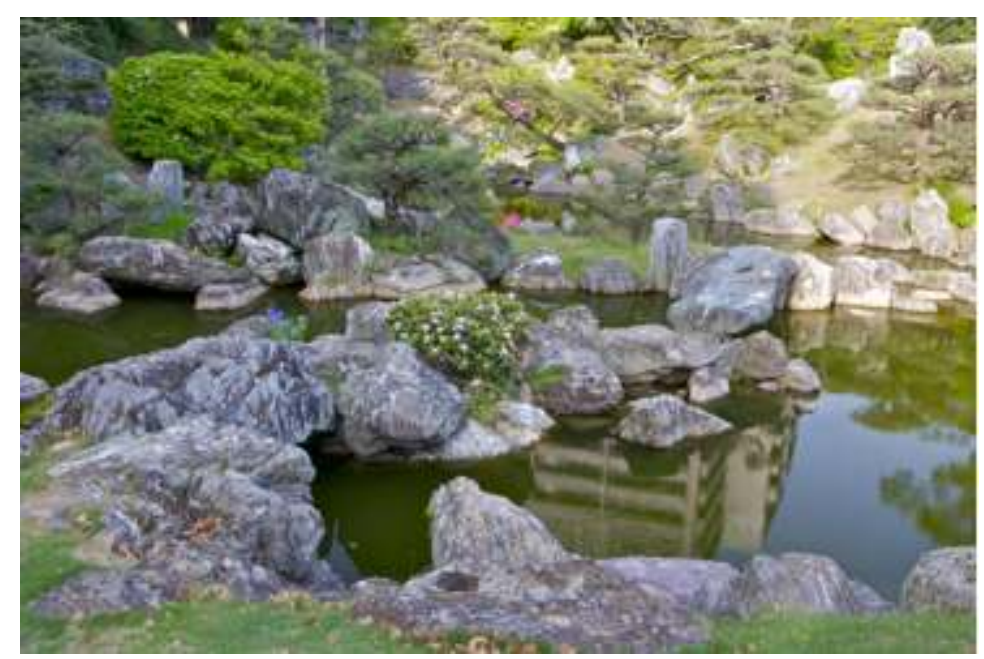

Source : Nicolas Fiévé

18 À l'époque de cette réalisation audacieuse, le daimyō Asano Nagaakira 浅野長晟 (1586-1632) dirigeait le fief de Wakayama, avant qu'il ne reçût en 1619 (Genwa 5) celui de Hiroshima 広島藩. Le fief de Kishū 紀州藩 (Wakayama), qui comprenait la province de Kii 紀伊国 et la moitié sud de la province d'Ise 伊勢国, un ensemble d'un revenu annuel de 540000 koku, est alors revenu à Tokugawa Yorinobu 徳川頼宣 (1602-1671) et le jardin du Nishi no maru (enceinte de l'Ouest) fut entièrement remanié cette année-là sous la direction d'Ueda Sōko. Pour réaliser ce jardin, Sōko utilisa la dénivellation naturelle du terrain d'une vingtaine de mètres, qu'il accentua en faisant creuser le site, afin de réaliser une gorge profonde, au fond de laquelle se jette un cours d'eau, tel un torrent de montagne. Un cheminement escarpé permet au visiteur de descendre le long de la montagne, de franchir un pont au-dessus d'une ravine, d'enjamber l'écoulement d'une chute d'eau, avant d'arriver au fond d'une combe encaissée entre les escarpements rocheux et là, debout sur des pierres plates placées au milieu d'un lac, de pouvoir contempler la verticalité grandiose de ce paysage imaginaire qui rappelle la Chine et les peintures de paysage de l'époque de Song. Jamais un jardin aristocratique de Kyōto n'avait eu recours à des dénivellations aussi abruptes sur une telle échelle (figure 10). 
Figure 10. Jardin du Nishi no maru 西の丸庭園 (8 $\left.200 \mathrm{~m}^{2}\right), 1619$ (Genwa 5), château de Wakayama 和歌山城, Ueda Sōko 上田宗箇 (1563-1650)

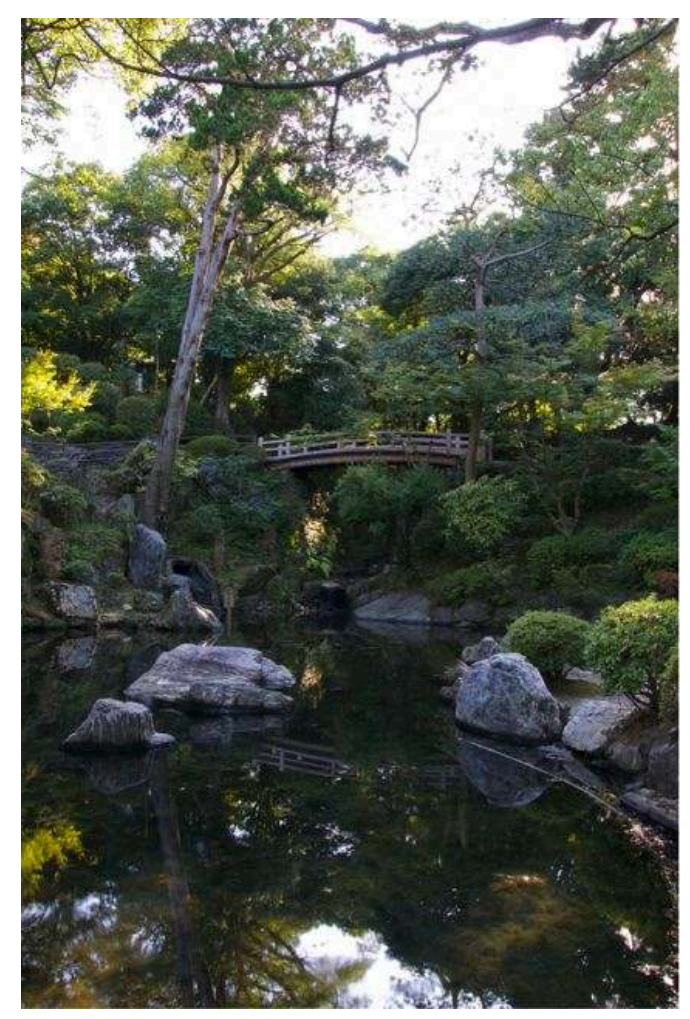

Source : Nicolas Fiévé

Après avoir reçu le fief de Hiroshima, un fief d'un revenu de 426000 koku qui couvre la province d'Aki安芸国 et la moitié de celle de Bingo 備後国, le seigneur Asano Nagaakira demande à Sōko de réaliser le parc de sa nouvelle résidence secondaire, située à 400 mètres environ du château de Hiroshima, en bordure de la rivière Kyōbashi. Là, à partir de 1620 (Genwa 6), Sōko dirige les travaux du Shukkei-en縮景園, un vaste jardin de quatre hectares, organisé autour d'un étang et pour lequel il conçoit aussi les pavillons de thé (figure 11). Ce parc paysager est remanié, au cours des années 1783 (Tenmei 3) et 1788 (Tenmei 8), par Shimizu Shichirō.uemon清水七郎右衛門, un jardinier invité de la capitale, soit située à plus de 350 kilomètres de route, qu'un homme du peuple comme Shichirō.uemon parcourait vraisemblablement à pied. Brûlés par la bombe en 1945, les pavillons de thé y furent reconstruits et la flore replantée depuis. C'est ce jardin conçu par Sōko que l'on peut encore contempler, avec son célèbre paysage évoquant le pont de pierre du Grand lac de l'Ouest à Hangzhou杭州, au milieu d'un lac parsemé de plusieurs îles-tortue et qu'enserrent trois collines artificielles boisées surmontées de kiosques ${ }^{10}$. 
Figure 11. Jardin Shukkei-en縮景園 (4 hectares)

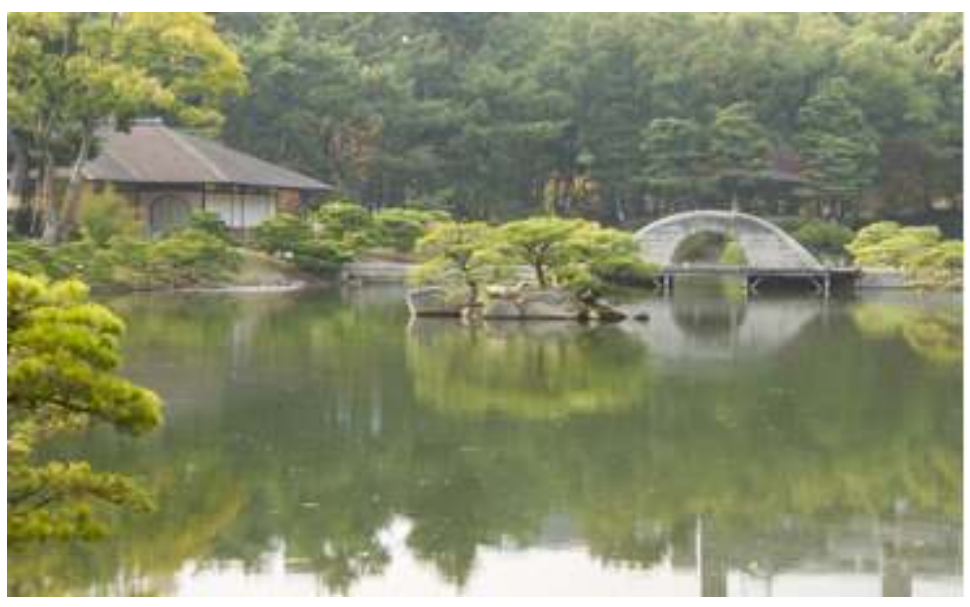

Du $7^{\text {er }}$ seigneur Asano Nagaakira (1586-1632) du fief de Hiroshima, conçu en 1620 (Genwa 6) par Ueda Sôko 上田宗箇 (1563-1650) et remanié entre 1783 (Tenmei 3) et 1788 (Tenmei 8) par le maître jardinier Shimizu Shichirō.uemon清水七郎右衛門.

Source : Nicolas Fiévé

Les exemples d'Enshū et de Sōko illustrent bien des aspects de l'évolution des pratiques en matière de conception de jardin survenue au début de l'époque d'Edo. Tous deux sont des hommes issus des régions centrales du Japon et des guerriers de rang modeste. Proche des milieux lettrés et artistiques de Kyōto, ils deviennent maitres de thé, après avoir reçu l'enseignement des plus grands maitres de leur temps. Tous deux furent au demeurant les fondateurs de leur propre tradition de l'art du thé : Enshū-ryū 遠州流et Ueda-rȳu 上田流, école Enshū et école Ueda, deux lignées réservées aux guerriers qui fleurirent jusqu'à la période moderne, jusqu'en 1955 pour l'école Ueda qui s'est éteinte avec le décès du $17^{\mathrm{e}}$ maître de thé Kake Jōdō 加計静堂, et toujours vivace pour la très réputée école Enshū. Tout au long de leur vie, ces deux hommes, qui se rencontrèrent à de nombreuses reprises, furent invités ici et là à réaliser de grands jardins, pour lesquels ils assuraient aussi la conception des pavillons et autres kiosque et belvédères : sukiya, chaya, chashitsu, azumaya, etc. Rétribués pour ces commandes, ce fut bien l'originalité de leurs créations qui les rendit célèbres aux quatre coins de l'archipel, participant ainsi à une nouvelle redistribution des savoirs de l'ancienne capitale impériale.

\section{Les manuels d'horticulture et de l'art des jardins}

21 Nonobstant, ce que pouvaient financer les hommes les plus influents de leur temps n'était pas à la portée de seigneurs ou de guerriers de rang plus modeste. En période de développement urbain et de circulation des hommes, l'écrit, sous la forme de manuel imprimé de composition des jardins, devient un vecteur non négligeable de la diffusion des connaissances en matière de paysage et d'horticulture. Les quelques manuscrits antérieurs à l'époque d'Edo mentionnés en début de la première partie de cet article étaient des pièces uniques, demeurées longtemps dans les mains d'un même propriétaire, c'est-à-dire des œuvres qui, malgré quelques copies, avaient fait l'objet d'une diffusion restreinte et réservée aux élites aristocratiques de Kyōto. Les livres imprimés, en revanche, de plus en plus nombreux au fur et à mesure que l'on avance dans l'époque d'Edo, ont été largement vulgarisés dans l'ensemble du pays et ont été le 
plus souvent rédigés ou compilés par des hommes de condition modeste: de simples guerriers, des fils de commerçants, voire quelques artistes issus des couches les plus basses de la société.

Dans le même temps, plusieurs livres chinois sur les jardins furent apportés au Japon et parfois imprimés et diffusés. Parmi les plus célèbres, le Michuan huajing 秘傳花鏡, (jap. Hiden kakyō), ou Transmission secrète du miroir des fleurs (1688), de Chen Haozi 陳添 子 (dates inconnues, $\mathrm{xVII}^{\mathrm{e}}$ siècle), connu au Japon grâce à l'édition de Hiraga Gennai 平 賀源内 (1728-1779), et que notre collègue Georges Métaillié a récemment réédité, rendant une part non négligeable de ce texte accessible au lecteur français ${ }^{11}$.

Un ouvrage de botanique comme le Sōmoku sodate-gusa 草木育種 (La Reproduction des plantes), publié en 1818 (Bunka 15) par Abe Rekisai 阿部櫟齊 (Abe Yoshitada 喜任, 1805-1870), un disciple du botaniste et spécialiste d'histoire naturelle Iwasaki Kan.en 岩 崎灌園 (1786-1842) ${ }^{12}$, n'aurait pu être rédigé sans une bonne connaissance du Michuan huajing, auquel il fait souvent des emprunts. Le Sōmoku sodate-gusa évoque tour à tour la culture et les techniques de reproduction des plantes en pot, les méthodes de taille et de ligature des bonsai 盆栽, la taille et le façonnage de la forme des pins, les sites d'entrepôt et le calendrier pour l'entretien des plantes et les outils du jardinier. Il se termine par un index par ordre syllabique (いろは) de 157 plantes, que Rekisai décrit et classe par famille, sur 42 feuillets (84 pages).

Le grand traité de Ji Cheng計成, le Yuanye 園冶 (Mise en forme des jardins, jap. En.ya), préfacé en 1631 par l'auteur et publié en Chine probablement en 1634, a été importé au Japon au XVIII ${ }^{\mathrm{e}}$ siècle. Il est inventorié dans les réserves des shōguns Tokugawa, le Momiji-yama bunko 紅葉山文庫ou Bibliothèque de la montagne des érables rouges, suite à l'importation en 1701 de trois fascicules, en 1712 de quatre autres fascicules, et en 1735 de l'intégralité du livre ${ }^{13}$. Mais en période de fermeture du pays aux influences étrangères, cet ouvrage chinois fut classé « livre interdit », kinsho 禁書! Il ne fut donc l'objet d'aucune diffusion grand public jusqu'à l'ère Taishō (1912-1926), ce qui n'exclut pas la connaissance de son contenu dans l'entourage du shōgun ${ }^{14}$.

Parmi les ouvrages japonais publiés à l'époque d'Edo, j'ai recensé une vingtaine de titres principaux, le plus souvent des livres illustrés. Restituant l'image des paysages artificiels, des arrangements de pierres et de collines, de l'implantation et de la forme des arbres, l'iconographie présente dans ces livres fut un vecteur de diffusion de formes stéréotypées du paysage, comme ce fut le cas dès le début du xviI siècle avec la publication du Tsukiyama teizō-den 築山庭造傳 (Transmission sur les styles de jardins en montagnes artificielles), un ouvrage majeur pour l'histoire des jardins d'Edo, rédigé en 1735 (Kyōhō 20) par Kitamura Enkinsai 北村援琴齊 (dates inconnues) ${ }^{15}$. 
Figure 12. Tsukiyama teizō-den 築山庭造傳 ( "Transmission sur les styles de jardins en montagnes artificielles »), 1735 (Kyōhō 20), de Kitamura Enkinsai 北村援琴齋 (dates inconnues)

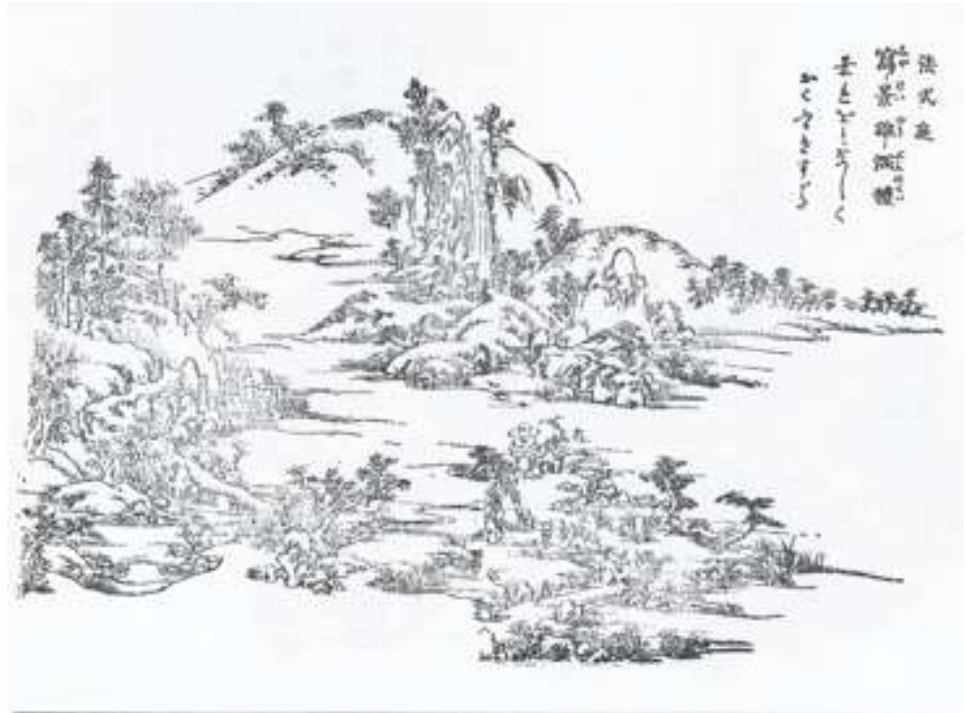

Règles de jardins : Paysage emprunté de type profond. Ici, le paysage est commun, mais l'arrière-plan est particulièrement profond.

Source : Nicolas Fiévé

Ce manuel emprunte l'essentiel de son texte à des textes plus anciens, comme le Sagaryū niwa kohō hiden no sho (Livre des traditions secrètes de l'école Saga sur les anciennes techniques de composition des jardins, 1395), cité plus haut, ou le Tsukiyama sansui-den 築山山水傳 (Transmission sur les paysages de montagnes artificielles), un livre publié quelques années plus tôt, en 1723 (Kyōhō 8) ${ }^{16}$. S'il n'innove pas, la large diffusion dont il est l'objet a eu un impact sur les pratiques, notamment dans les provinces éloignées de la capitale (figure 12). De même, la version complétée de ce livre qu'édite en 1828 (Bunsei 11) Ritōken Akisato 離島軒秋里 ( ?-vers 1830 ?), adjointe d'une seconde partie rédigée de la main de ce dernier ${ }^{17}$, demeure sans aucun doute le plus célèbre des ouvrages sur les jardins de la fin de la période, tant par l'ampleur de sa diffusion, que par l'originalité de son contenu. On ne connaît à peu près rien de son auteur, ni de la formation qu'il aurait pu recevoir. Pourtant, la présentation qu'il donne des paysages a façonné durablement l'art des jardins modernes du Japon. L'ouvrage innove par rapport à ses prédécesseurs par sa présentation des styles shintai 眞體, gyōtai 行體 et sōtai 草體, dont le vocable est hérité de la calligraphie chinoise - style régulier, zhen, intermédiaire, xing, cursif, cao - des différentes catégories de paysages en collines artificielles (tsukiyama sansui 築山山水). Il présente en outre les typologies des jardins de courettes intérieures (tsubo-niwa 坪庭) et des jardins de thé (chatei 茶 庭), comme celles d'éléments de mobilier de jardin : vasques à eau, dites «bols pour se rincer les mains » (chōzu-bachi 手水鉢) et lanternes de pierre (seki tōrō 石燈籠). Une présentation de plusieurs jardins renommés de Kyōto, dont les exemples n'avaient pas été inclus dans le Miyako rinsen meishō-zue都林泉名勝図会 (《Récit illustré sur les jardins renommés de la capitale ", 1799), un autre ouvrage d'Akisato qui fut un succès d'édition, complète cette présentation singulière des jardins de la période.

Publié en 1799 (Kansei 11) par Ritōken Akisato, en cinq fascicules, le Miyako rinsen meishō-zue a inventorié une centaine de temples et de jardins de Kyōto, dont ceux de célèbres maisons de thé, dont il donne une description, adjointe parfois d'une 
illustration. Comme les autres ouvrages de Ritōken, le Miyako rinsen meishō-zue a été un succès d'édition dès sa publication et l'objet d'une large diffusion, comme en atteste le grand nombre de copies et de rééditions qui circulent encore de nos jours ici et là chez les bouquinistes. Le livre doit sa célébrité à la qualité et au détail des gravures sur bois, à une époque où les jardins renommés de Kyōto servent d'exemple pour la conception des jardins d'Edo et des autres villes du Japon. Sa large diffusion montre combien la connaissance des jardins de Kyōto faisait l'objet d'un engouement dans le Japon d'Edo ${ }^{18}$.

Il faut ici souligner qu'en dépit d'un assez grand nombre de titres nouveaux, rares sont les textes vraiment originaux. Un examen attentif des sources révèle une majorité de copies partielles ou intégrales des ouvrages les plus anciens - et cela qu'il s'agisse de manuscrits ou de livres imprimés. Que des textes vieux, parfois de plusieurs siècles, aient été remaniés, édités et présentés comme des nouveautés est un phénomène qui, dans une certaine mesure, a également contribué à la relative homogénéité des pratiques.

Il n'est pas fortuit que les deux plus anciens manuscrits connus sur l'art des jardins présentés dans la première partie de cet article, le Sakutei-ki et le Senzui narabi ni yagyō no zu, soient passés des mains de nobles de Cour résidant à Kyōto, à celle de la puissante maison Maeda du fief de Kaga, sans doute à l'époque où, vers 1676 (Enpō 4), le $5^{\mathrm{e}}$ daimyō Maeda Tsunanori 前田綱紀 (1643-1724) entreprend les travaux de la partie basse des jardins de l'enceinte extérieure du château de Kanazawa, au cours desquels il fait creuser l'étang Renchi-tei 蓮池庭 et installer la grande chute d'eau que l'on peut aujourd'hui encore y admirer (figure 13). Le jardin a été agrandi tout au long de l'époque d'Edo, jusqu'à devenir à la fin de la période le très renommé Kenroku-en兼六 園, un parc de dix hectares désigné depuis lors comme l'un des trois plus renommés du Japon, Nihon sanmeien 日本三名園 ${ }^{19}$. 
Figure 13. Grande chute d'eau, dite Midori-taki 翠瀧, du jardin Renchi-tei 蓮池庭 (milieu du $\mathrm{XVII}$ siècle), conçu pour le cinquième seigneur du fief de Kaga, Maeda Tsunanori (1623-1724)

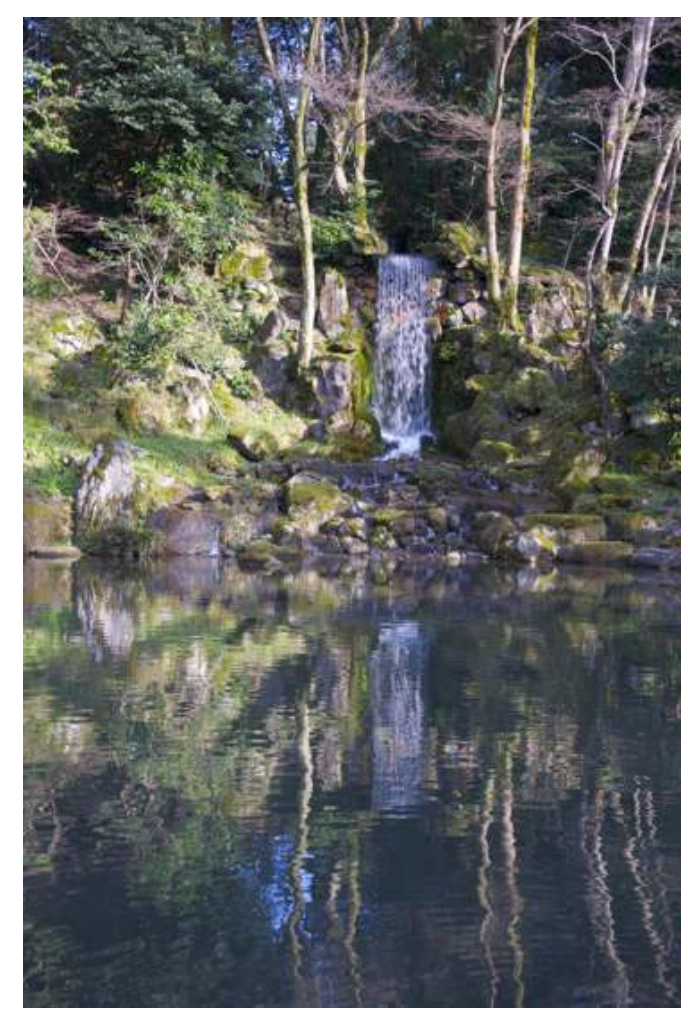

Parc Kenroku-en 兼六園 (Kanazawa).

Source : Nicolas Fiévé.

Cette copie du Sakutei-ki était restée la propriété des Fujiwara durant le Moyen Âge (une des plus importantes familles de la noblesse japonaise), mais elle est transmise à la maison Maeda à l'époque de Tsunanori, alors qu'il entre en possession dans le même temps du plus ancien manuscrit connu du Senzui narabi ni yagyō no zu, la copie de 1466, qui est demeurée la propriété des Maeda jusqu'à nos jours ${ }^{20}$. Le transfert d'œuvres d'une telle valeur pour l'histoire des jardins, produites à l'origine par des nobles et réservées à leur propre usage, s'il révèle l'hégémonie économique et politique des daimyō sur les nobles de Cour, il témoigne aussi du vif intérêt que ces grands seigneurs portaient aux anciens savoir-faire de la noblesse de Kyōto en matière de paysage.

Au cours de l'époque d'Edo, le Sakutei-ki et le Senzui narabi ni yagyō no zu n'ont pas donné lieu à une riche filiation, ce qu'expliquent sans doute les changements de modes de vie. Le Sansui-shō en était, au XIII ${ }^{\mathrm{e}}$ siècle, une émanation directe; des œuvres tardives, comme le Dōji kuden-sho 童子口傅書 (Écrits sur les traditions orales rapportées par les disciples), dont on possède une copie datée de 1742 (Kanpō 2), et le Musō-ryū chitei 無空 流治庭 (Aménagement des jardins de l'école Musō) ${ }^{21}$, publié en 1799 (Kansei 11) ${ }^{22}$, s'en inspirent aussi dans une certaine mesure, certainement en raison d'un regain du désir de connaissance, à cette période, de l'ancienne culture aristocratique de Kyōto.

Il en va autrement pour le Saga-ryū niwa kohō hiden no sho, manuscrit de la fin du XIV ${ }^{e}$ siècle qui dépeint des savoir-faire développés dans les milieux bouddhiques, à une époque où les shōgun Ashikaga sont au fait de leur pouvoir. La réalisation de la copie de 1395 est contemporaine de l'enfance de Zen.ami 善阿弥 (1386 ?-1482 ?), le maître jardinier qui a réalisé plusieurs jardins majeurs de la période, comme celui de 
l'Inryōken 蔭涼軒 (pavillon de la Fraîcheur), celui du temple Shōkokuji ou de l'Izumidono 泉殿 (pavillon de la Source) du palais shōgunal, deux célèbres jardins depuis longtemps disparus. Témoin d'un âge d'or des jardins de Kyōto, le Saga-ryū niwa kohō hiden no sho a donné lieu à une riche filiation qui ne s'est jamais, depuis lors, épuisée, une filiation d'œuvres qui furent le plus souvent à la source d'une large diffusion de l'art des jardins au cours de l'époque d'Edo, tant géographique que dans l'ensemble des couches sociales de la société. On trouve dans cette riche généalogie les titres suivants : Sōami Tsukiyama sansui-den 相阿弥築山山水傳 (Transmission de Sōami sur les paysages de montagnes artificielles) [date et auteur inconnus] ${ }^{23}$; Tsukiyama sansui-den 築山山水傳 (Transmission sur les paysages de montagnes artificielles), livre imprimé de 1723 (Kyōhō 8) ${ }^{24}$; Teihei tsukigata-den 庭坪築形傅 (Transmission sur les formes artificielles des jardins), publié en 1737 (Genbun 2); Teizō shodan no den 庭造初段の傳 (Fondements de la composition des jardins), copie de 1792 (Kansei 4); Tsukiyama teizō-den de Kitamura Enkinsai et Tsukiyama teizō-den kōhen de Ritōken Akisato déjà cités plus haut, dont les multiples éditions au cours de l'époque d'Edo et à l'ère Meiji ont assuré une large diffusion. Il serait souhaitable enfin de mentionner une dernière œuvre signée Ritōken Akisato, l'Iwagumi sono.u yaegaki-den 石組園生八重垣傳 (Transmission sur les assemblages de pierres, les jardins et les huit épaisseurs de haies) ${ }^{25}$, publié en 1827 (Bunsei 10), qui présente un catalogue illustré des différentes haies, barrières et autres éléments de séparations (kaki 坦) du jardin, des ponts (hashi 橋), des portes en bois (kido 木戸), des puits (ido 井戸), des pierres ornementales (ishi 石), des assemblages de pierres (ishigumi 石組), des pavements de pierres (tobi ishi 飛石), des lanternes (seki tōrō) ou des vasques à eau (chōzu-bachi), que l'on peut placer ou reproduire dans son jardin $(\text { figure } 14)^{26}$.

Figure 14. Ritōken Akisato離島軒秋里, Iwagumi sono.u yaegaki-den 石組園生八重垣傳 ("Transmission sur les assemblages de pierres, les jardins et les huit épaisseurs de haies »), 1827

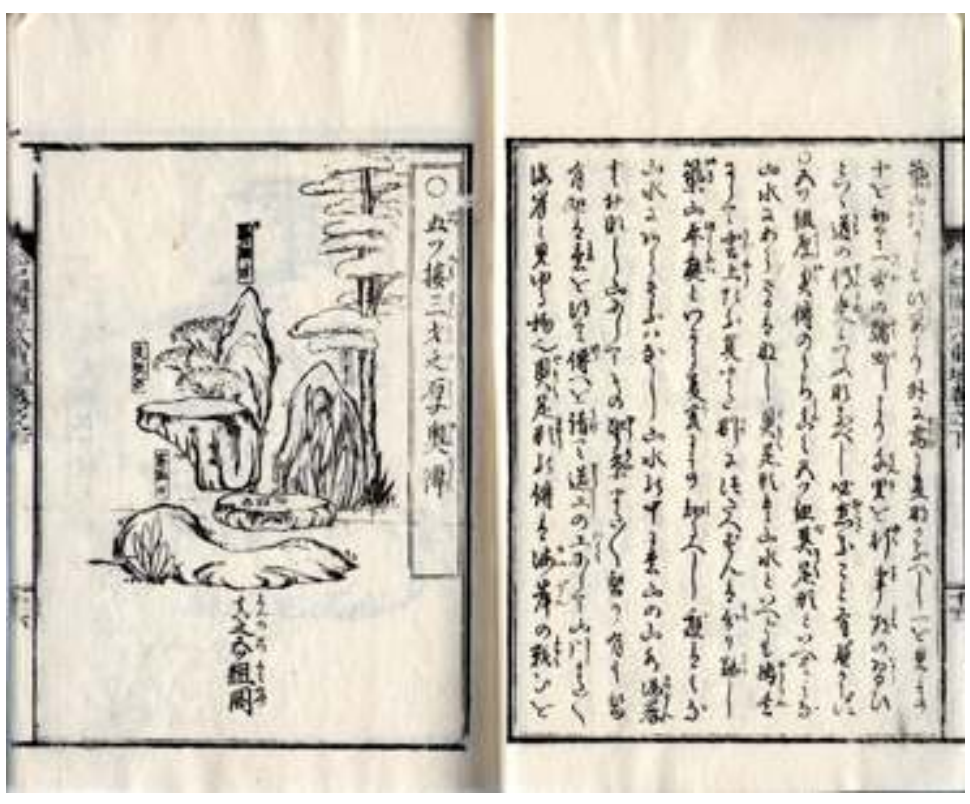

Source : Nicolas Fiévé

Contrairement aux manuels du début de l'époque d'Edo qui restent souvent des ouvrages théoriques utiles à la conception d'un vaste ensemble de jardins destinés aux élites, les ouvrages d'Akisato sont des catalogues de formes de paysages et d'éléments 
de jardins destinés à un public plus modeste, sans doute des populations citadines nouvellement enrichies qui souhaitaient avoir un jardin autour leur maison de ville. Les ouvrages présentent ainsi des dispositifs paysagers de taille relativement réduite, ce qui explique leur succès auprès du public : à l'époque de l'industrialisation du Japon, ces ouvrages servent de modèle pour concevoir les jardins des habitations de la nouvelle classe moyenne, dite des "cols blancs", qui se forme à la fin du XIX et du début du $\mathrm{xx}^{\mathrm{e}}$ siècle. Le Zukai Teizōhō 圖解庭造法 (Techniques de composition des jardins, livre illustré), publié en 1890 par Honda Kinkichirō 本多錦吉郎 (1850-1921), atteste de cette vogue des manuels de paysagisme auprès des classes moyennes (figure 15) ${ }^{27}$.

Figure 15. Honda Kinkichirō 本多錦吉郎 (1850-1921), Zukai Teizōhō 圖解庭造法 (《Techniques de composition des jardins ", livre illustré), 1890

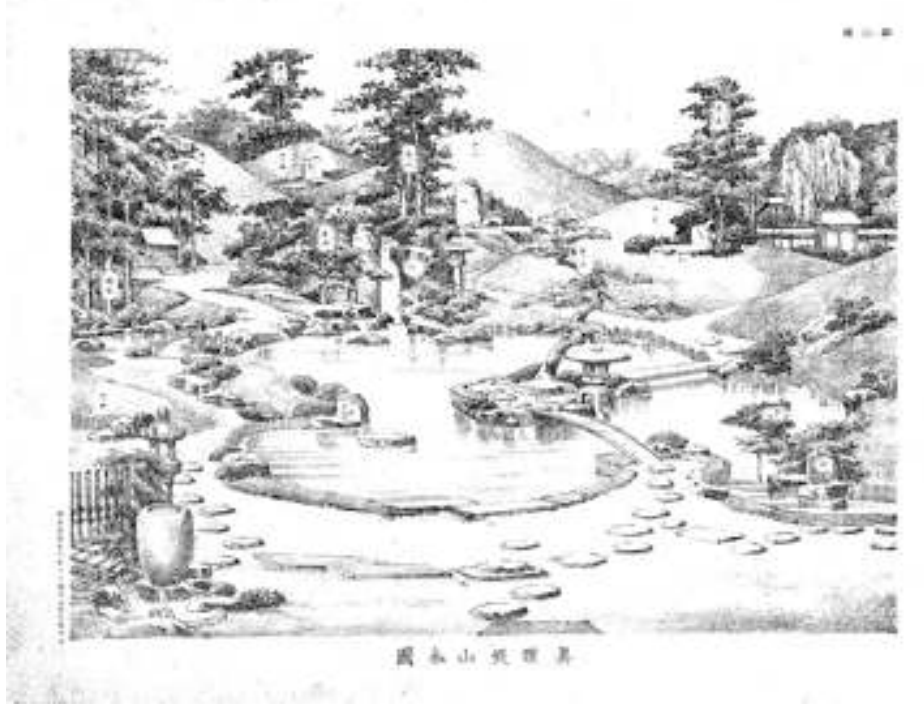

À l'époque où il rédige ce livre, Honda Kinkichirō n'avait pas reçu de formation d'historien ni d'horticulteur, encore moins de jardinier. S'il était certes un peintre de paysage, il avait été formé à l'école occidentale, yōga 洋画, et avait déjà publié quelques manuels sur la peinture européenne, notamment des recueils de modèles de dessins ${ }^{28}$. En d'autres termes, l'auteur du Teizōhō n'était pas un spécialiste des jardins, sans doute, tout au plus, un amateur éclairé. Il a quarante ans lorsqu'il publie le Zukai Teizōhō, son premier livre sur les jardins, dont l'aspect le plus novateur ne se trouve pas dans le texte, mais dans les quarante dessins couleur de jardins ou d'éléments de jardins qu'il a réalisés en perspective, à la manière occidentale, un procédé qu'il adopte dans tous ses ouvrages (figures 15 et 16). Les perspectives du Zukai Teizōhō copient fidèlement les gravures du Tsukiyama teizō-den, l'ouvrage publié soixante-deux années plus tôt par Ritōken Akisato, illustrations auxquelles Honda a ajouté six planches originales de porches d'entrée avec un accès pour les voitures, où se mêlent des motifs paysagers japonais et occidentaux. Le texte du Zukai Teizōhō résume d'importants passages des deux volumes du Tsukiyama teizō-den de Ritōken Akisato. Après une introduction d'une dizaine de pages, l'auteur reprend, image par image, le commentaire des illustrations du manuel de l'époque d'Edo: Shintai kazan zenzu 眞體假山全圖 (Illustration des jardins en montagne artificielle de forme shin), Gyōtai kazan zenzu 行體假山全圖 (Illustration des jardins en montagne artificielle de forme gyō), Sōtai kazan zenzu 草體假山全圖 (Illustration des jardins en montagne artificielle de forme sō). Il définit ensuite les trois mêmes 
catégories, shin, gyō et sō, mais pour les « jardins sans relief» (hiraniwa 平庭), c'est-àdire sur terrain plat, avant de donner un ensemble assez varié de vues de jardins, que complète un catalogue des éléments qui les composent: les haies, les ponts, les lanternes et les vasques en pierre.

Figure 16. Jardin du Seiju-in 成就院 du temple Kiyomizu-dera 清水寺

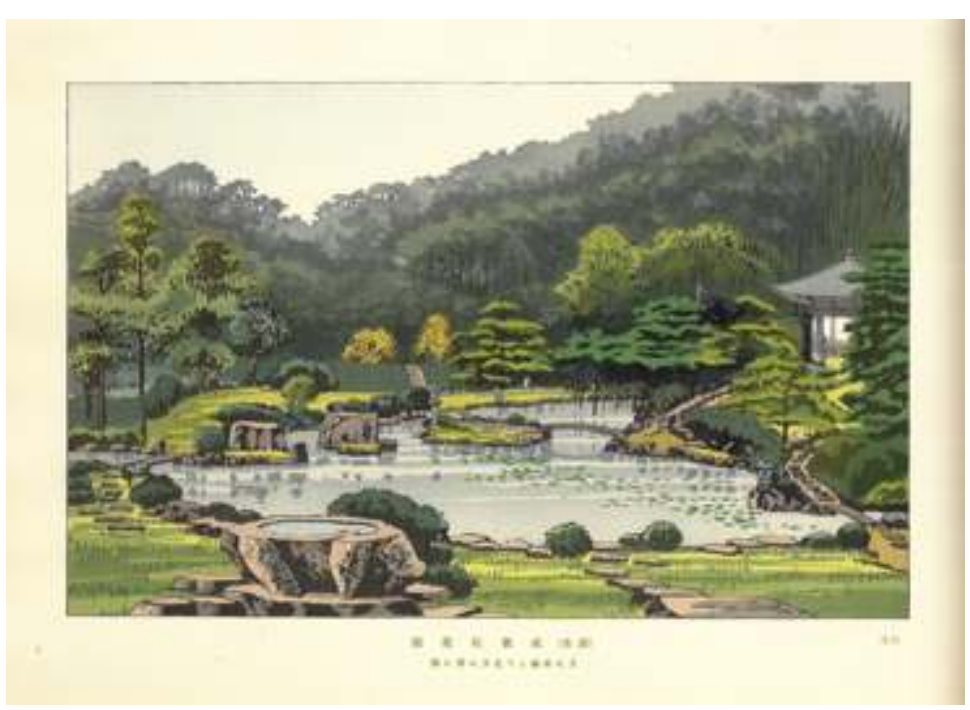

Estampe d'après un dessin de en perspective, à la manière occidentale réalisée par Honda Kinkichirō 本多錦吉郎 (1850-1921), illustration tirée du Nihon meien zufu 日本名園畗譜 ( Recueil illustré des jardins renommés du Japon »), 1911.

Le Zukai Teizōhō se présente ainsi comme un manuel grand public destiné à aider les classes moyennes de l'ère Meiji (1868-1912) à concevoir le jardin qu'elles aimeraient se faire construire dans leur habitation banlieusarde. Une large part du succès du livre, publié dans un contexte de modernisation de l'habitat, mais à une époque où l'art du jardin occidental demeurait le plus souvent inconnu, doit être attribuée à la modernité des illustrations et à la clarté du propos de l'auteur.

Si l'on ajoute, à l'ensemble des titres mentionnés dans cet article, une dizaine de traités rédigés au cours de l'époque d'Edo sur les jardins de thé roji 露地, - des manuels qui forment une filiation indépendante des autres ouvrages -, une liste de plus de quarante titres dessine trois grandes familles thématiques de manuels : une première composée de textes sur l'ordonnancement des jardins de plaisance de l'ancienne aristocratie, une deuxième dans laquelle une large place est accordée à la composition plastique des paysages artificiels des jardins médiévaux et prémodernes, une troisième, enfin, sur le jardin de thé, le modeste « chemin » qui mène au pavillon de thé, un lieu de repos et de méditation dont chaque élément est choisi selon les besoins de l'austère pratique de la cérémonie du thé.

\section{Vers une approche moderne et scientifique du jardin}

À la fin du XIX siècle, la création de parcs publics dans les villes nouvellement industrialisées avait placé le gouvernement de Meiji devant la nécessité de former rapidement des ingénieurs modernes, maîtrisant les techniques occidentales du paysagisme et de l'horticulture. L'École d'agriculture et des forêts de Tōkyō (Tōkyō 
nōrin gakkō 東京京農林學校), ancêtre de la faculté d'agronomie de l'université de Tōkyō, ouvre ses portes en 1886. En 1908, c'est au tour de l'École d'horticulture de la préfecture de Tōkyō (Tōkyō fūritsu engei gakkō 東京府立園藝學校), ancêtre de l'actuelle École supérieure d'horticulture de la préfecture de Tōkyō, bientôt suivie par d'autres universités de province, à Nara, à Ōsaka et à Kyōto. Ces départements, où l'on enseignait les techniques agricoles et la gestion des forêts, dispensaient, pour la première fois au Japon, des enseignements sur les parcs et les jardins, qu'ils fussent japonais ou d'Occident, sur leurs techniques, leur mise en œuvre et leur histoire. Ces nouveaux enseignements bouleversèrent les anciennes pratiques relatives au paysage. De même que les architectes formés dans les facultés d'ingénierie remplaçaient à cette époque les maîtres d'œuvre qu'avaient été depuis des siècles les charpentiers, des ingénieurs des parcs et des jardins (zōen gakusha 造園学者), diplômés des facultés d'agronomie, supplantaient les anciens maîtres jardiniers, niwa-shi 庭師, opérant ainsi une profonde mutation de l'art du paysage japonais ${ }^{29}$.

Après les lettrés nobles de Kyōto qui jadis concevaient eux-mêmes les jardins de leur habitation, les seigneurs domaniaux de l'époque d'Edo ont sollicité, dès le xvII siècle, des paysagistes issus des milieux de guerriers modestes pour assurer les conceptions de leurs jardins. Quant au Japon moderne de l'ère Meiji, il forme des ingénieurs paysagistes pour la conception des parcs publics. Alors que les lettrés de l'ancienne Kyōto avaient rédigé pour leur propre compte des notes manuscrites sur l'art du paysage, des professionnels ont édité à l'époque d'Edo des catalogues et autres manuels sur l'art des jardins que l'on diffusait le plus largement possible pour les nouvelles classes moyennes de la société urbaine. Le début $\mathrm{du} \mathrm{xx}^{\mathrm{e}}$ siècle voit la publication des premiers ouvrages scientifiques qui rassemblent les connaissances occidentales en matière d'agronomie. Il voit naître dans le même temps les premiers historiens modernes de l'art des jardins, qui étudient scientifiquement les jardins à partir de la philologie des textes anciens, de l'archéologie des sites historiques, de l'étude spatiale des dispositifs paysagers et de la classification des espèces végétales et des essences minérales qui les composent. Des travaux qui sont à la source des politiques et des techniques de conservation et de restauration des jardins historiques, et qui furent mis en place à partir des années 1930.

\section{BIBLIOGRAPHIE}

Fiévé, Nicolas, «Le récit sur les hauts lieux de la capitale. Essai sur le rôle du meisho dans la constitution d'une ville-mémoire ", dans Japon pluriel. Actes du premier colloque de la Société française des études japonaises, Arles, Éditions Philippe Piquier, 1995, p. 305-318.

Fiévé, Nicolas, «Les pavillons du thé : philosophie et fonctionnalisme d'une architecture », dans Christine Shimizu (sous la dir. de), Les Arts de la cérémonie du thé, Dijon, Éditions Faton, 1996, p. 48-85. 
Fiévé, Nicolas, « Kyōto's famous places: collective memory and monuments in the Tokugawa period », dans Nicolas Fiévé and Paul Waley (eds.), Japanese Capitals in Historical Perspective: Power, Memory and Place in Kyōto, Edo and Tōkyō, London, Routledge-Curzon Press, 2003, p. 153-171.

Fiévé, Nicolas, « Les sources japonaises, médiévales et prémodernes, des premiers ouvrages publiés en Europe et aux États-Unis sur les jardins japonais - Landscape Gardening in Japan (1893), de Josiah Conder ; The Gardens of Japan (1928), de Harada Jirō ; Art of the Landscape Gardens in Japan (1935), de Tamura Tsuyoshi », dans Fiévé Nicolas et Jacquet B. (sous la dir. de), La réception de l'architecture et des jardins japonais en occident, de la fin du XIX siècle à 1945, Paris, École française d'Extrême-Orient, coll. « Études thématiques ", à paraître, en 2012.

Hiroshima-ken Kyōikuiin-kai 広島県教育委員会 (ed.), Shukkeien-shi 縮景園史 (Histoire du Shūkkeien), Hiroshima, Hiroshima-ken bunkasai kyōkai, 1984.

Honda Kinkichirō本多錦吉郎, Teishi - gagaku kyōju-hō 梯氏畫學教授法 (Méthode d'enseignement de la peinture de Monsieur Tei [Thomas Tate]), Tōkyō, Monbushō, 1879.

Honda Kinkichirō本多錦吉郎, Zukai teizō-hō 圖解庭造法 (Méthode illustrée de composition des jardins), Tōkyō, Dandansha, 1890.

Honda Kinkichirō本多錦吉郎, Shōgakuga tehon 小學畫手本 (Modèles pour l'apprentissage du dessin), Tōkyō, Dandansha shoten, 12 fascicules publiés à partir de 1890.

Honda Kinkichirō, Nihon meien zufu日本名園畗譜 (Recueil illustré des jardins renommés du Japon), Tōkyō, Shōsaiei, 1911.

Ji Cheng, Yuanye. Le traité du jardin (1634), traduction et commentaires de Che Bing Chiu, , Besançon, Les Éditions de l'imprimeur, coll. « Jardins et Paysages », 1997.

Chen Haozi, Miroir des fleurs. Guide pratique du jardinier amateur dans la Chine au XVII siècle (Plon, 1900), traduit du chinois par J. Halphen, édition préparée par G. Métaillié, Arles, Actes Sud, 2006.

Mori Osamu, Kobori Enshū no sakuji 小堀遠州の作事 (Les réalisations de Kobori Enshū), Nara, Bunkazai hogo iinkai, 1966.

Mori Osamu, Kobori Ensh̄̄ 小堀遠州, Tōkyō, Yoshikawa kōbunkan, 1987.

Noma Kōshin 野間光辰 (ed.), Miyako rinsen meishō-zue 都林泉名勝圖会 (Récit illustré sur les jardins renommés de la capitale), Kyōto, Rinsen shoten, coll. « Shinshū Kyōto sōsho 新修京都聚書 》, vol. IX, 1994

Sawada Tenzui沢田天瑞, Nagoyajō no teien 名古屋城の庭園 (Les jardins du château de Nagoya), Nagoya, Nagoyajō shinkyōkai, 1967.

Shigemori Mirei 重森三玲, Nihon teien-shi taikei日本庭園史大系9 (Grande compilation sur l'histoire des jardin japonais, vol. IX), Momoyama no niwa 桃山の庭2 (Jardins de l'époque Momoyama, volume II), Tōkyō, Shakai shisō-sha, 1972.

Uehara Keiji (ed.), Tsukiyama teizō-den (zenpen) kaisetsu築山庭造伝(前編)解説, Tōkyō, Kajima shoten, coll. « Zōen kosho sōsho », vol. I, 1965.

Uehara Keiji (ed.), Tsukiyama teizō-den (kōhen) kaisetsu 築山庭造伝(後編)解説, Tōkyō, Kajima shoten, coll. « Zōen kosho sōsho », vol. II, 1965.

Yang Fuhei楊馥妃, «Chūgoku to nihon teien hikaku kenkyū : « Yuanye » to « Sakuteiki » to no hikaku kai shite中国と日本の庭園比較研究：『園治』と『作庭記』との比較を介して», Nihon kenchiku gakkai kantō shibu hōkokusho 9034, Tōkyō, Nihon kenchiku gakkai, 2001, p. 593. 
Yoshimura Iwao 吉村嚴 (éd.), Teizō kosho shūroku 庭造古書集録 (Recueil des manuels anciens sur les jardins), Tōkyō, Yūmei shobō, 1970.

\section{Liste des manuscrits et livres anciens cités dans l'article}

Dōji kuden-sho 童子口傳書 (Écrits sur les traditions orales rapportées par les disciples), copie de 1742 (Kanpō 2).

Iwagumi sono.u yaegaki-den 石組園生八重坦傳 (Transmission sur les assemblages de pierres, les jardins et les huit épaisseurs de haies), 1827 (Bunsei 10).

Michuan huajing (jap. Hiden kakyō) 秘傳花鏡 (Transmission secrète du miroir des fleurs), 1688.

Miyako rinsen meishō-zue都林泉名勝困会 (Récit illustré sur les jardins renommés de la capitale), 1799 (Kansei 11).

Musō-ryū chitei 無空流治庭 (Aménagement des jardins de l'école Musō), 1799 (Kansei 11).

Saga-ryū niwa kohō hiden no sho 嵯峨流庭古法秘傳之書 (Livre des traditions secrètes de l'école Saga sur les anciennes techniques de composition des jardins), XIV siècle (?).

Sakutei-ki 作庭記 (Notes sur la composition des jardins), copie de 1289 (Shōō 2).

Sansui-shō 山水抄 (Notes sur les paysages), non daté.

Senzui narabi ni yagyō no zu 山水抖野形畗 (Illustrations des paysages et des formes de plaines), colophon de 1654 (Jōō 3).

Sōami Tsukiyama sansui-den 相阿弥築山山水傳 (Transmission de Sōami sur les paysages de montagnes artificielles) [non daté].

Sōmoku sodate-gusa 草木育種 (La reproduction des plantes), 1818 (Bunka 15).

Teihei tsukigata-den 庭坪築形傳 (Transmission sur les formes artificielles des jardins), 1737 (Genbun 2). Teizō shodan no den 庭造初段の傳 (Fondements de la composition des jardins), copie de 1792 (Kansei 4).

Tsukiyama sansui-den 築山山水傳 (Transmission sur les paysages de montagnes artificielles), 1723 (Kyōhō 8).

Tsukiyama teizō-den 築山庭造伝 (Transmission sur les styles de jardins en montagnes artificielles), 1735 (Kyōhō 20).

Tsukiyama teizō-den kōhen 築山庭造伝後編, 1828 (Bunsei 11).

\section{NOTES}

1. Voir dans ce même dossier l'article détaillé que consacre Emmanuel Marès à Kobori Enshû.

2. Mori, Osamu, Kobori Enshū no sakuji 小堀遠州の作事 (Les Réalisations de Kobori Enshū), Nara, Bunkazai hogo iinkai, 1966, p. 67-70.

3. Ibid., p. 33-38 et p. 45-47; Mori, Osamu, Kobori Enshū 小堀遠州, Tōkyō, Yoshikawa kōbunkan, 1987, p. 133-139.

4. Enshū a été chargé de remanier le jardin du palais impérial de Kyōto, mais aucune source ne démontre avec certitude qu'il a pu s'occuper du jardin de Katsura, contrairement à ce que la tradition a rapporté. 
5. Fiévé, Nicolas, «Structure de l'espace des pavillons de thé. Développement des arts et de la pensée à la fin du Moyen Âge ", mémoire de maîtrise de japonais classique sous la direction de Jacqueline Pigeot, Paris, Uuniversité de Paris VII, 1989 (260 p.), p. 75.

6. Le sotetsu蘇鉄 est une plante à graines spermatophyte, qui n'appartient ni à la famille des fougères, ni à celle des palmiers, bien qu'elle y ressemble. Originaire des îles Ryūkyū 琉球, elle fut introduite à Kyūshū 九州, dans les fiefs en commerce avec les îles du Sud. Les plantations actuelles sont antérieures à la fondation du jardin de Nijō.

7. Shigemori Mirei 重森三玲, Nihon teien-shi taikei日本庭園史大系9, (Grande compilation sur l'histoire des jardin japonais, vol. 9), Momoyama no niwa 桃山の庭2 (Jardins de l'époque Momoyama, vol. 2), Tōkyō, Shakai shisō-sha, 1972, p. 35-46.

8. Shigemori Mirei, ibid., p. 35-46.

9. Sawada Tenzui沢田天瑞, Nagoya-jō no teien 名古屋城の庭園 (Les Jardins du château de Nagoya), Nagoya, Nagoya-jō shinkyōkai, 1967, p. 79-120.

10. Shigemori Mirei 重森三玲, Nihon teien-shi taikei日本庭園史大系 9 , (Grande compilation sur l'histoire des jardin japonais, vol. 9), op. cit., p. 89-102 ; Hiroshima-ken Kyōikuiin-kai (ed.), Shukkeienshi 縮景園史 (Histoire du Shūkkei-en), Hiroshima, Hiroshima-ken bunkasai kyōkai, 1984, 202 p.

11. Une partie du livre a été traduite par J. Halphen et publiée chez Plon en 1900. Voir la réédition de cette traduction, préparée et présentée par Métaillié, Georges, Miroir des fleurs. Guide pratique du jardinier amateur dans la Chine au XVII siècle, Arles, Actes Sud, 2006, 312 p.

12. J'ai utilisé l'édition de 1818, publiée à Edo chez Yamashiroya Sabei 山城屋佐兵衛, conservée à la bibliothèque du département d'économie de l'université de Kyōto.

13. Dates établies d'après les recueils des importations par bateau. Voir l'article de Yang Fuhei楊 馥妃, «Chūgoku to nihon teien hikaku kenkyū: «Yuanye » to «Sakuteiki » to no hikaku wo kaishite中国と日本の庭園比較研究:『園治』と『作庭記』との比較を介して》 ( Étude comparative sur les jardins chinois et japonais : à partir d'une comparaison entre le Yuanye et le Sakuteiki), Nihon kenchiku gakkai kantō shibu hōkokusho 9034, Tōkyō, Nihon kenchiku gakkai, 2001, p. 593.

14. On se référera en français à la traduction de notre ami Che Bing Chiu, Ji Cheng, Yuanye. Le traité du jardin (1634), Besançon, Les Éditions de l'imprimeur, coll. «Jardins et Paysages », 1997, $316 \mathrm{p}$.

15. Réédition dans Uehara Keiji (éd.), Tsukiyama teizō-den (zenpen) kaisetsu築山庭造伝(前編)解説, Tōkyō, Kajima shoten, coll. « Zōen kosho sōsho », 1965, vol. 1, 110 p.

16. Cette diffusion de formes stéréotypées fut elle-même véhiculée en Occident (en particulier au États-Unis) au XIX ${ }^{\mathrm{e}}$ siècle et au début du $\mathrm{xx}^{\mathrm{e}}$ siècle, grâce aux premiers ouvrages publiés en anglais sur les jardins. Voir Fiévé, Nicolas, «Les sources japonaises, médiévales et pré-modernes, des premiers ouvrages publiés en Europe et aux États-Unis sur les jardins japonais - Landscape Gardening in Japan (1893), de Josiah Conder ; The Gardens of Japan (1928), de Harada Jirō ; Art of the Landscape Gardens in Japan (1935), de Tamura Tsuyoshi ", dans Fiévé, Nicolas et Jacquet, Benoît (sous la dir. de), La réception de l'architecture et des jardins japonais en occident, de la fin du XIX siècle à 1945, Paris, EFEO, coll. « Études thématiques », à paraître en 2012.

17. Réédition dans Uehara Keiji (ed.), Tsukiyama teizō-den (kōhen) kaisetsu 築山庭造伝(後編)解説, Tōkyō, Kajima shoten, coll. « Zōen kosho sōsho », 1965, vol. 2, 100 p.

18. Parmi les nombreuses éditions modernes de l'ouvrage, je conseillerais celle dirigée par Noma Kōshin 野間光辰, Miyako rinsen meishō-zue 都林泉名勝圖会 (Récit illustré sur les jardins renommés de la capitale), Kyōto, Rinsen shoten臨川書店, coll. «Shinshū Kyōto sōsho 新修京都聚書 》, 1994, vol. 9, 569 p. Sur les recueils de lieux célèbres de Kyōto, voir Fiévé, Nicolas, « Le récit sur les hauts lieux de la capitale. Essai sur le rôle du meisho dans la constitution d'une ville-mémoire ", Japon pluriel. Actes du premier colloque de la Société française des études japonaises, Arles, Éditions Philippe Picquier, 1995, p. 305-318, un texte repris en anglais dans "Kyoto's famous places : collective memory and monuments in the Tokugawa period», dans Nicolas Fiévé and Paul Waley (eds.), 
Japanese Capitals in Historical Perspective: Power, Memory and Place in Kyoto, Edo and Tokyo, London, Routledge-Curzon Press, 2003, p. 153-171.

19. Il s'agit des trois parcs Kenrokuen de Kanazawa, Kōrakuen d'Okayama et Kairakuen de Mito (voir la première partie de l'article, figures 5 et 9). L'origine de cette dénomination n'est pas claire, mais il semblerait qu'elle se propage à la fin de l'époque d'Edo, alors que les seigneurs de ces fiefs ouvraient ces jardins au public à certaines occasions.

20. Cette copie est conservée au Sonkei-kaku bunko 尊経閣文庫, les archives qui rassemblent à Kanazawa les fonds des anciennes bibliothèques de la maison Maeda.

21. Je reprends ici la lecture donnée par Uehara Keiji ; Uehara Keiji (ed.), Yokei-zukuri niwa no zu. Hoka san-kosho, op. cit., 1972, p. 51.

22. Réédition dans Uehara Keiji, ibid., 1972, p. 89-93.

23. Réédition dans Yoshimura Iwao 吉村嚴 (éd.), Teizō kosho shūroku 庭造古書集録 (Recueil des manuels anciens sur les jardins), Tōkyō, Yūmei shobō, 1970, p. 16-18.

24. Réédition dans Uehara Keiji, ibid., p. 69-77.

25. Les « huit épaisseurs de haies ", mentionnées dans le titre proviennent d'un passage de la mythologie rapportée dans le Kojiki 古事記 (712), alors que Susanoo no mikoto est à la recherche d'un emplacement idéal pour bâtir une « auguste maison », miya 宮, et y vivre avec son épouse. Il compose le poème suivant: " Huit nuages s'amoncellent/huit épaisseurs de haies d'Izumo/pour m’y réfugier avec mon épouse/j'ai bâti huit épaisseurs de haies/ces huit épaisseurs de haies! 夜 久毛多都 / 伊豆毛夜弊賀岐 / 都麻碁微爾 / 夜弊賀岐都久流 /曾能夜弊賀岐袁 (Yakumo tatsu八 雲立つ/Izumo yaegaki出雲八重坦/tsuma gomi ni 妻籠みに/yaegaki tsukuru八重垣作る/sono yaegaki woその八重坦を)», Kojiki 古事記 (Récit des choses anciennes), Tōkyō, Shōgakukan, coll. « Nihon koten bungaku zenshû »,1973, vol. 1, p. 90-91.

26. J'ai utilisé pour cette étude une édition trouvée l'an dernier chez un bouquiniste de Kyōto, datée de Meiji 27 (1894) et publiée à Ōsaka par la maison Kashiwara Keibundō 柏原奎文堂 (wahon en 4 fascicules).

27. Honda Kinkichirō, Zukai teizōhō 圖解庭造法 (Méthode illustrée de composition des jardins), Tōkyō, Dandansha 團々社, 1890, 13 p., 26 pl. et 39 illustr.

28. Honda Kinkichirō, Shōgakuga tehon 小學畫手本 (Modèles pour l'apprentissage du dessin), Tōkyō, Dandansha shoten團々社書店, 12 fascicules publiés à partir de 1890 ; Teishi - gagaku kyōju-hō 梯氏 畫學教授法 (Méthode d'enseignement de la peinture de Monsieur Tei [Thomas Tate]), Tōkyō, Monbushō, 1879, 3, 78, 20 p.

29. Voir dans ce même dossier l'article que Sylvie Brosseau consacre à l'une des figures majeures de cette génération, le paysagiste Honda Seiroku 本多静六 (1868-1952).

\section{RÉSUMÉS}

La période prémoderne (1573-1867) inaugure un nouveau développement des jardins dans bien des domaines et les seigneurs domaniaux, nouvelles élites issues de la classe des guerriers, aiment se faire bâtir de vastes parcs paysagers dépassant souvent une dizaine d'hectares, ce qui est un phénomène nouveau. Vivant loin de Kyōto, qui jusqu'alors avait été le berceau de l'art des jardins, ces seigneurs font appel à des spécialistes chargés de la conception des parcs paysagers et de leur architecture: la figure de l'architecte-paysagiste naît ainsi au Japon au début du XVII ${ }^{\mathrm{e}}$ siècle. Dans le même temps, la diffusion des pratiques sur l'ensemble du territoire donne 
lieu à la rédaction de plusieurs manuels de paysagisme ou d'horticulture qui sont imprimés, et qui deviennent des succès d'édition en raison de la banalisation progressive du jardin dans l'habitat de toutes les classes de la société.

The pre-modern period (1573-1867) marks the start of a new development of gardens in many areas, and the state lords - the new elite coming from the warriors class - enjoy having vast landscape parks built; these parks often spread over ten hectares, which is a new phenomenon. Living far from Kyoto, which had been the cradle of gardening art until then, these lords call upon specialists who are in charge of the conception of landscape parks and their architectures: thus, the figure of the landscape-architect was born in Japan at the beginning of the $17^{\text {th }}$ century. At the same time, the spreading of these activities over the whole territory has lead to the writing of several handbooks on landscape architecture or horticulture, which are printed, and which have become successful because of the progressive spread of the garden in the housing of every class of the society.

\section{INDEX}

Mots-clés : Kobori Enshū, Ueda Sōko, assemblage de pierres, paysage miniature, montagne artificielle

Keywords : Kobori Enshū, Ueda Sōko, stones assembling, miniature landscape, artificial mountain

\section{AUTEUR}

\section{NICOLAS FIÉVÉ}

Directeur d'études à l'École pratique des hautes études, section des sciences historiques et philologiques. Chaire d'histoire de l'architecture et des jardins du Japon. Membre du réseau Japarchi.

nfieve[at]gmail[dot]com 